\title{
Mitral valve movement : a study using an ultrasound technique
}

\author{
C. F. P. Wharton and L. Lopez Bescos \\ From the Cardiac Department, Guy's Hospital, London
}

The movement of the anterior leaflet of the mitral valve has been recorded with an ultrasound echo technique. The intrinsic mobility of the valve cusps and the rate of ventricular filling are thought to influence the closure of the valve during diastole. Atrial contraction occurs at the end of ventricular diastole and reopens the valve before the mitral valve returns to the closed position before the onset of ventricular systole.

The relation of the opening snap and third heart sound to the movement of the cusp is shown.

In mitral stenosis ventricular systole occurs when the mitral valve is still far away from the closed position and the rapid movement of the cusp to the closed position may be the cause of the high intensity vibrations of the first heart sound. The EF slope (representing the rate of the closing movement of the cusp in end diastole) is decreased and a good correlation has been found with the degree of stenosis. After mitral valvotomy the EF slope increases significantly.

The validity of these methods in assessing mitral incompetence or relative predominance of stenosis or incompetence in mixed mitral lesions is discussed.

The ultrasound cardiograph is a fairly simple and completely atraumatic technique with proven diagnostic value in mitral valve disease. In addition, because of the new type of information that is given, it has potential as a research tool which is, as yet, largely unexplored.

Edler and Hertz (1954) first reported the possibility of recording the movement of various heart structures by the ultrasound method. It has since been shown that it is possible to identify a characteristic echo arising from the anterior leaflet of the mitral valve (Edler, I96r; Edler et al., I96r ; Gustafson, 1966; Yoshida et al., 1961). This paper reports some of the results obtained by applying this technique to a group of patients. These patients were also studied by other means and the ultrasound cardiograph has been correlated with these other observations.

\section{Subjects and methods}

The movement of the mitral valve was recorded by ultrasound technique in 145 patients with heart disease and 12 normal subjects.

Haemodynamic data were obtained by routine right and left heart catheterization; mitral incompetence was estimated by left ventricular angiography. When the patients underwent mitral valve operation the valve area was estimated, and the degree of incompetence and calcification were assessed by the surgeon using previously defined criteria.

The ultrasound records were obtained using an

Received 19 November 1969.
Eskoline 20 ultrasonoscope which has a 2.5 megacycle barium titinate crystal and a nominal frequency of 1000 pulses/second. Ultrasound cardiograph tracings were recorded either by direct polaroid photography from the oscilloscope of the instrument or by means of a multichannel photographic or direct writing recorder (mingograph). In the latter cases an analogue gate was used to isolate the mitral valve echo and to transfer it to the recorder (Kingsley et al., 1967). The ultrasound transducer is applied to the anterior chest wall $\mathrm{I}$ to $4 \mathrm{~cm}$. from the left sternal edge in the 3 rd or 4 th interspace where the mitral valve echo can usually be obtained (Edler, I966).

\section{Results}

Analysis and correlation of mitral valve movement with events of cardiac cycle Fig. I schematically represents the tracing of the normal movement of the anterior mitral cusp as recorded with this technique, together with the simultaneous electrocardiogram and phonocardiogram tracing. Forward or opening movement of the cusp towards the anterior chest wall is represented by an upright deflexion in the tracing; the $\mathrm{E}$ point represents the mitral cusp at its most anterior position. Recession of the cusp from the anterior chest wall, as occurs in closing of the 


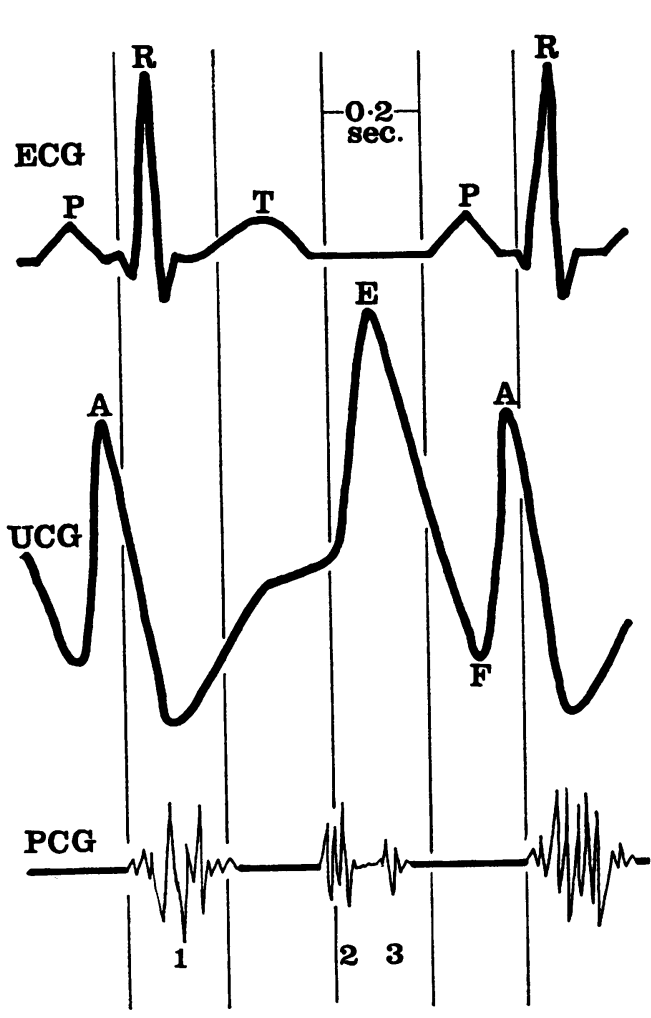

FIG. I Schematic representation of the ultrasound cardiograph tracing of mitral valve movement, showing its relation to the electrocardiogram and phonocardiogram. Movement of the cusp towards the transducer (anterior chest wall) is represented by upward displacement in the tracing. The $A$ deflexion represents opening of the valve with atrial systole. $E$ is the initial diastolic opening followed by the EF segments which is due to partial closure during mid-diastole.

valve, is recorded as a downward deflexion in the ultrasound cardiograph tracings. The $\mathbf{A}$ wave of the ultrasound cardiograph is regularly related to the $P$ wave of the electrocardiogram and represents movement of the mitral valve associated with atrial contraction. The total (over-all) amplitude of valve movement can be determined from the over-all vertical displacement of the tracing. The speed of closure of the valve leaflet during diastole can be measured by the slope of the EF segment (Edler, 1966).

The effect of the timing of atrial concentration on the speed of closure of the cusp, measured by the EF slope, was shown in a patient in complete heart block with an artificial pacemaker at a rate of $70 / \mathrm{min}$. No abnormality of the mitral valve was found either at cardiac catheterization or operation for calcific aortic stenosis. Fig. 2 shows the effect of the varying relation between atrial contraction and ventricular systole, on closure of the cusp. Some of the complexes from a continuous mingograph recording have been selected and show the EF slope and a less distinct upward wave, the $A$ wave, the latter bearing a constant relation to the $P$ wave of the electrocardiogram.

When the A wave occurs in late diastole, just before the succeeding systole, it fits into the record in a normal fashion. When the PR interval becomes longer than $0.32 \mathrm{sec}$. the A wave becomes incorporated into the EF segment and the initial slope of this segment increases from 70 to $124 \mathrm{~mm}$. per second; the mitral valve reaches the closed position before the onset of ventricular systole. If the PR interval is longer than 0.50 sec., atrial contraction occurs during ventricular systole and has no effect on the valve closure movement recorded on the ultrasound cardiogram.

Simultaneous phonocardiograms and ultrasound cardiograms from patients with mitral valve disease (Fig. 3) show that the opening snap occurs at the end of the rapid opening movement, beginning $0.03 \mathrm{sec}$. before the $E$ point. In mitral stenosis it is seen that the onset of ventricular systole occurs before the mitral valve has reached the fully closed (most downward) point and the cusp is still in a relatively open position.

The third heart sound (Fig. 4) occurs 0.02 sec. after the maximal opening of the mitral valve ( $E$ point). The mid-diastolic murmur follows when the mitral valve is in a more closed position.

Clinical application of ultrasound cardiogram in patients with mitral valve disease One hundred patients with mitral valve disease have been studied; 47 of them had pure or dominant mitral stenosis and 20 pure mitral incompetence, as assessed at cardiac catheterization or operation.

As shown in the Table, mitral stenosis tends to produce a conspicuous reduction of the EF slope and some decrease in the amplitude of movement. Provided the amplitude of movement is greater than $10 \mathrm{~mm}$., a fairly close correlation is seen between the EF slope and the mitral valve area (Fig. 6). This correlation is maintained though the dispersion is greater (Fig. 7) when the enddiastolic gradient and the mean left atrial pressure are plotted against the EF slope in the same group of patients. In 4 cases when the amplitude of movement was less than 


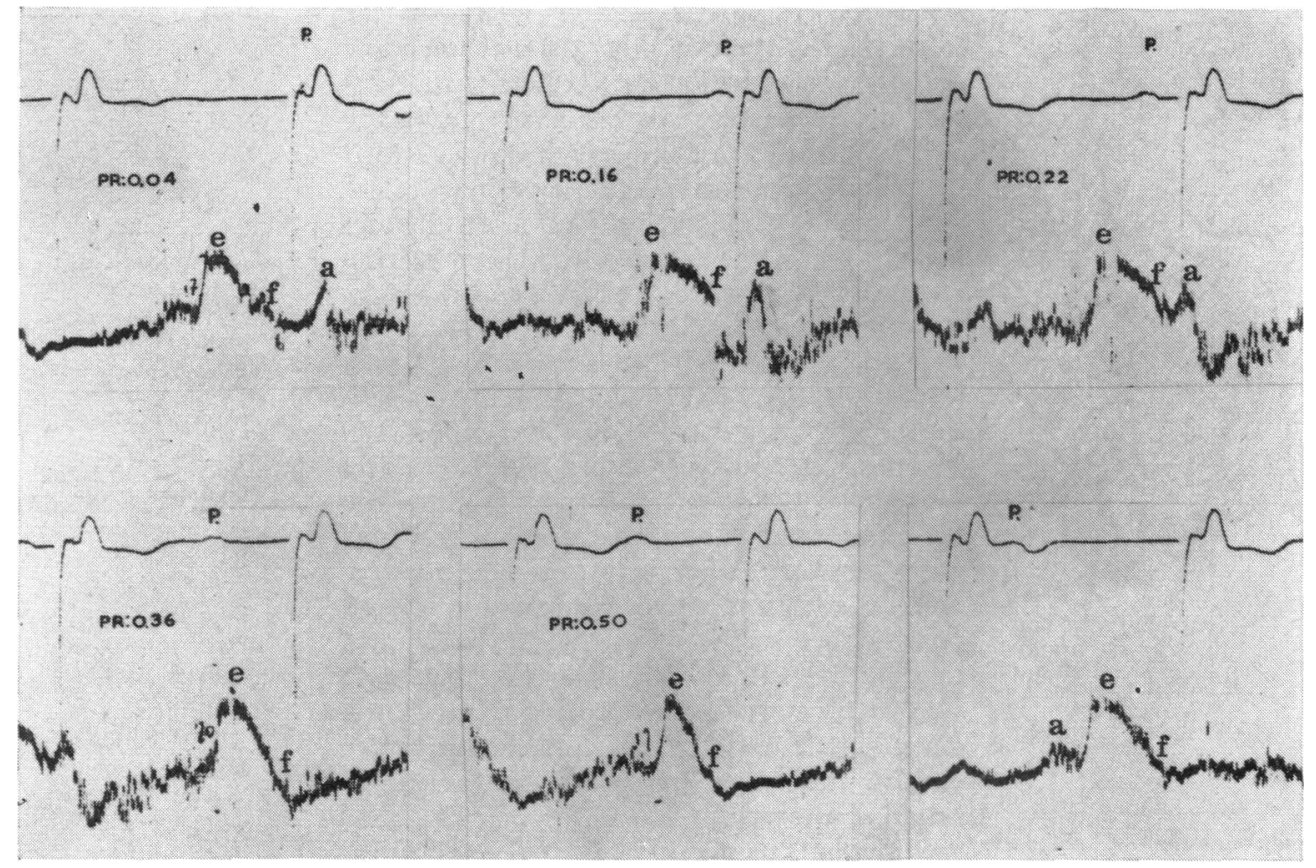

FIG. 2 Complete heart block with an artificial pacemaker. The complexes shown have been selected from a long continuous tracing to show the effect of varying $P R$ intervals on the speed of closure of the mitral valve.

TABLE Mean values of EF slope and amplitude of movement in normal subjects, patients with pure mitral stenosis, and patients with pure mitral incompetence

\begin{tabular}{|c|c|c|c|c|}
\hline \multirow[b]{2}{*}{$\begin{array}{l}\text { No. } \\
\text { of } \\
\text { cases }\end{array}$} & \multicolumn{2}{|c|}{$\begin{array}{l}\text { EF slope } \\
(\mathrm{mm} . / \mathrm{sec} .)\end{array}$} & \multicolumn{2}{|c|}{$\begin{array}{l}\text { Maximal ampli- } \\
\text { tude }\end{array}$} \\
\hline & Limits & Mean & Limits & Mean \\
\hline
\end{tabular}

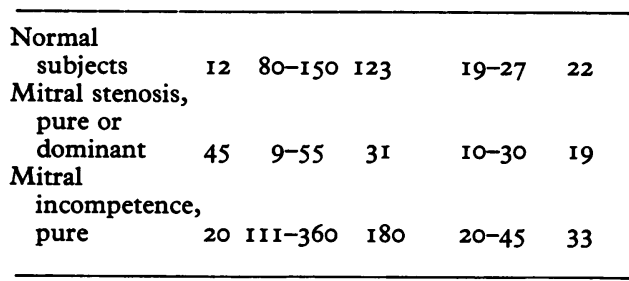

Io $\mathrm{mm}$. the mitral valve was found to be very distorted and immobile at operation, and these cases had given a stenotic pattern, though significant and sometimes dominant regurgitation was found. When the amplitude is reduced considerably, it is difficult to predict the dominant valve lesion, though the information that the valve is likely to be distorted, fibrosed, or calcified is of value.

Mitral incompetence tends to have an opposite effect on the ultrasound cardiogram tracing but there is some overlap with normal values (Table) (Segal, Likoff, and Kingsley, I967a).

In 2 I patients with mixed mitral stenosis and incompetence, a fairly characteristic pattern was observed (Fig. 3). The EF segment starts with a rapid deflexion followed by a plateau (Segal, Likoff, and Kingsley, I967b). The slope of the first segment has been of value in predicting the dominant component of the mixed lesion; when it was less than $45 \mathrm{~mm}$./sec., stenosis was dominant. The method has proved helpful in determining the significance of the systolic murmur in the presence of mitral stenosis (Wharton, 1968, 1969).

In all Io patients who underwent effective mitral valvotomy, the EF slope increased by Io to $42 \mathrm{~mm}$./sec. after operation (Fig. 5) (Effert, 1967).

\section{Discussion}

The normal mitral valve has a characteristic pattern of movement during diastole. After a rapid opening deflexion, there is a slower backward movement interrupted by the atrial contraction, after which the closing movement is quicker, bringing the valve to a closed or near closed position before ventricular systole occurs, provided atrial contraction occurs during diastole with a PR interval longer than $0 \cdot 0$ i sec.

The EF slope represents the speed at 


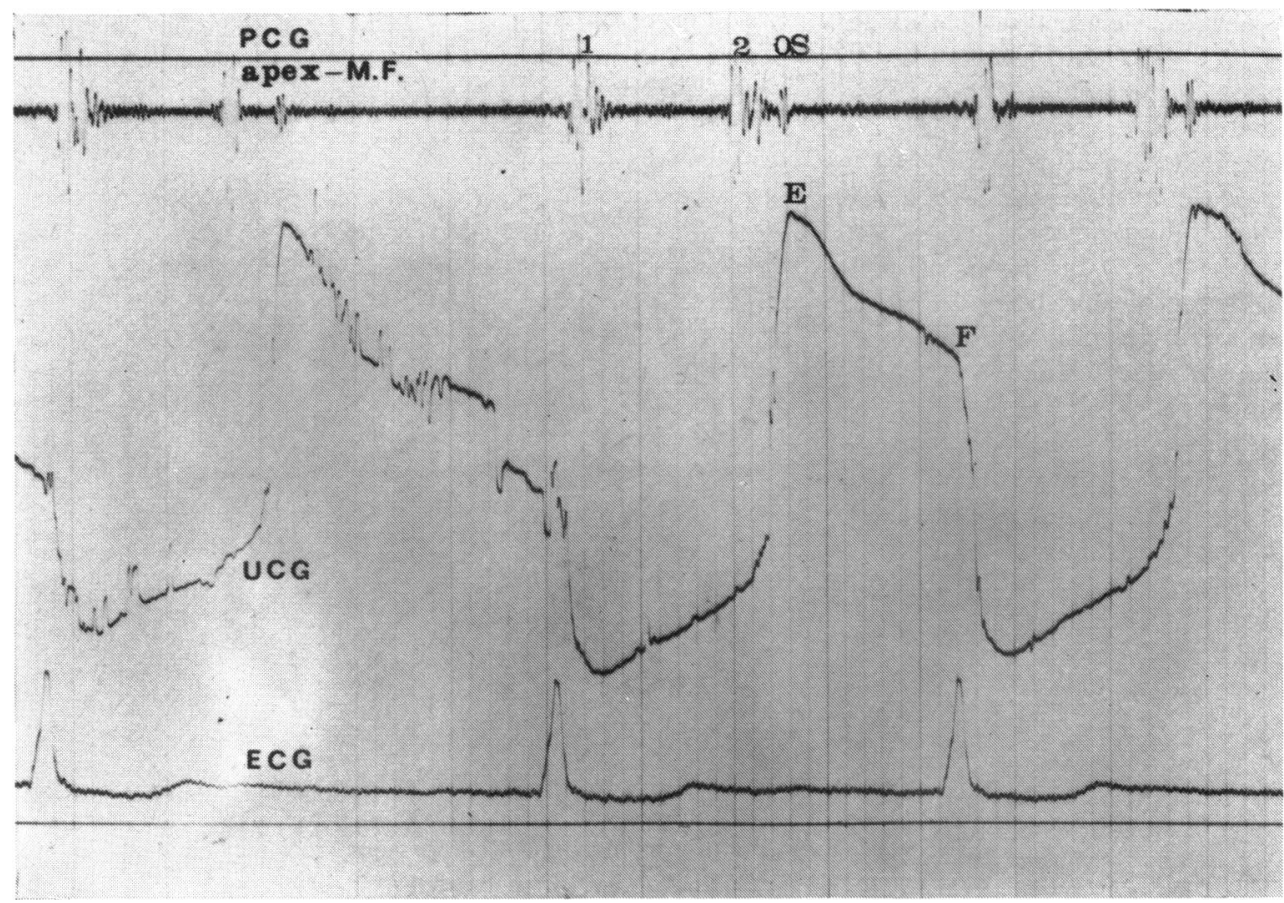

FIG 3 Simultaneous ultrasound cardiogram and phonocardiogram from a patient with mixed mitral valve disease. Opening snap starts $0.03 \mathrm{sec}$. before the $E$ point, and is related to an inflexion in the DE segment (rapid opening movement of the cusp). Initial EF slope, $44 \mathrm{~mm} . / \mathrm{sec}$. Amplitude $27 \mathrm{~mm}$.

FIG. 4 Simultaneous ultrasound cardiogram and phonocardiogram from a patient with dominant mitral and aortic incompetence. Loud third heart sound (3) starting 0.02 sec. after $E$, when the valve is at its maximally open position. The mid-diastolic murmur occurs when the valve is more closed. Initial EF slope $109 \mathrm{~mm} . / \mathrm{sec}$. Amplitude $40 \mathrm{~mm}$.

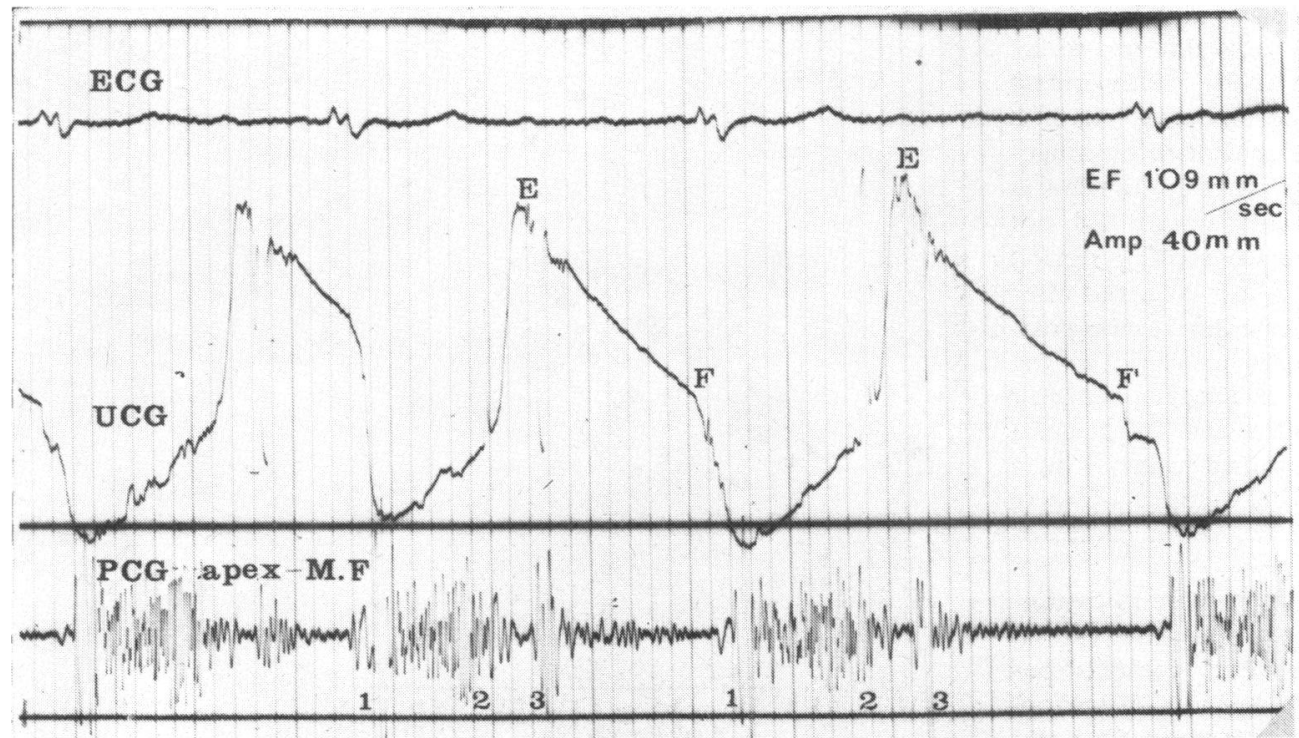


which the mitral valve recedes from the transducer during early and mid-diastole (Edler, 196I). If atrial systole occurs simultaneously with or immediately after mitral valve opening, the EF slope increases and is probably related to an increase in the rate of protodiastolic ventricular filling (Edler, I96I).

In patients with mitral stenosis the EF slope becomes flattened and the position of the valve at the end of the diastole is much more open than normal (Edler, I966). Hence, when ventricular systole occurs, the cusps are brought together from a greater distance. This is probably a factor responsible for the increased intensity of the first heart sound in mitral stenosis.

The amplitude of movement measured on the ultrasound cardiogram represents the displacement of the valve cusp from the closed to the open position. It is normally about $22 \mathrm{~mm}$. and may be reduced in patients with mitral stenosis, probably due to reduced mobility of the stenosed valve (thickening of the cusps, fusion of the commissures, and/or subvalvar apparatus). The increased amplitude of movement found in mitral incompetence and other conditions such as aortic incompetence (Wharton, 1969) is more diffcult to explain and, though statistical correlations have been made, it appears that dilatation of the left ventricle would play a part at least in the cases where the amplitude is over $30 \mathrm{~mm}$. The ultrasound cardiogram of mitral stenosis is not obscured by the presence of aortic regurgitation, and aortic stenosis does not interfere with the movement of the mitral valve as seen by ultrasound cardiography (Edler, 1966).

Simultaneous phonocardiograms and ultrasound cardiograms in patients with mitral stenosis suggest that the opening snap is related to the end of the rapid opening movement of the valve (Edler, 1966; Kingsley et al., 1967). The third heart sound did not seem to be associated with any rapid deflexion in the mitral valve tracing and occurred after the valve had reached its maximal open position, presumably during the rapid filling phase of the ventricles. The diastolic murmur recorded immediately after the third heart sound occurs while the mitral valve is in a more closed position and the speed of valve closure after the third heart sound decreases significantly.

The clinical value of the ultrasound cardiogram in the pre- and post-operative assessment of patients with mitral stenosis has already been reported by one of us (Wharton, 1968 1969), and our results tend to agree

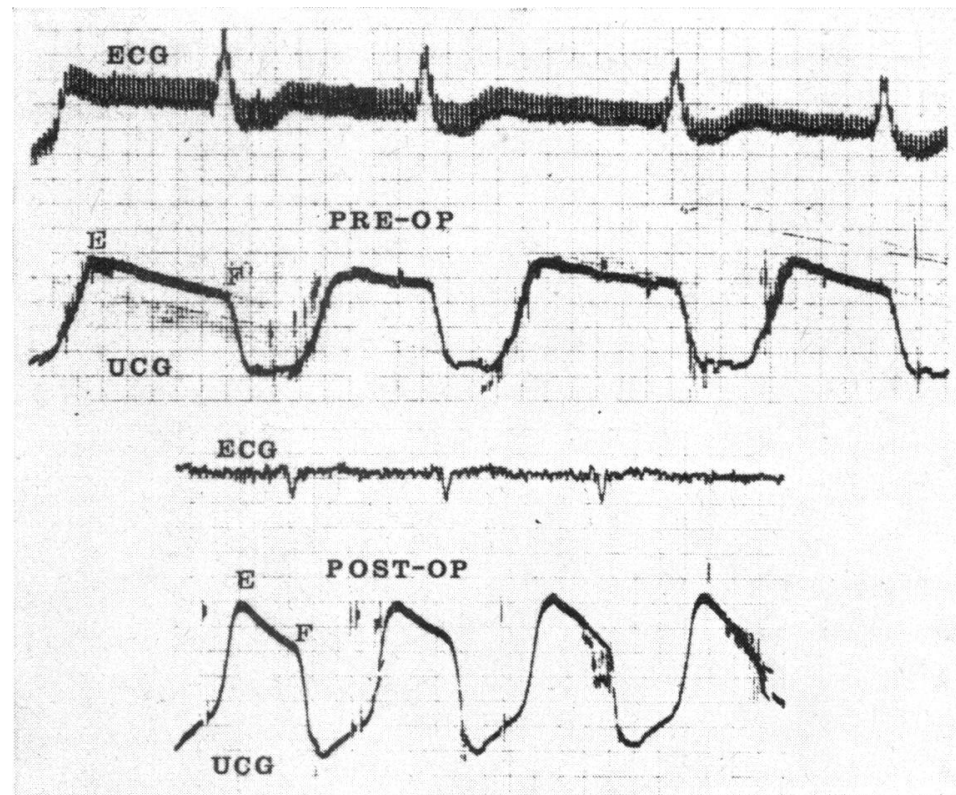

FIG. 5 Ultrasound cardiogram tracing before and after mitral valvotomy from a patient with pure mitral stenosis. Pre-operatively, estimated valve area $0.85 \mathrm{~cm} .^{2}, E F$ slope 13 $\mathrm{mm}$. $/ \mathrm{sec}$. Amplitude $23 \mathrm{~mm}$. Post-operatively, EF slope $37 \mathrm{~mm}$./sec. Amplitude $30 \mathrm{~mm}$.

FIG. 6 EF slope from ultrasound cardiogram tracings plotted against valve area in patients with mitral stenosis.

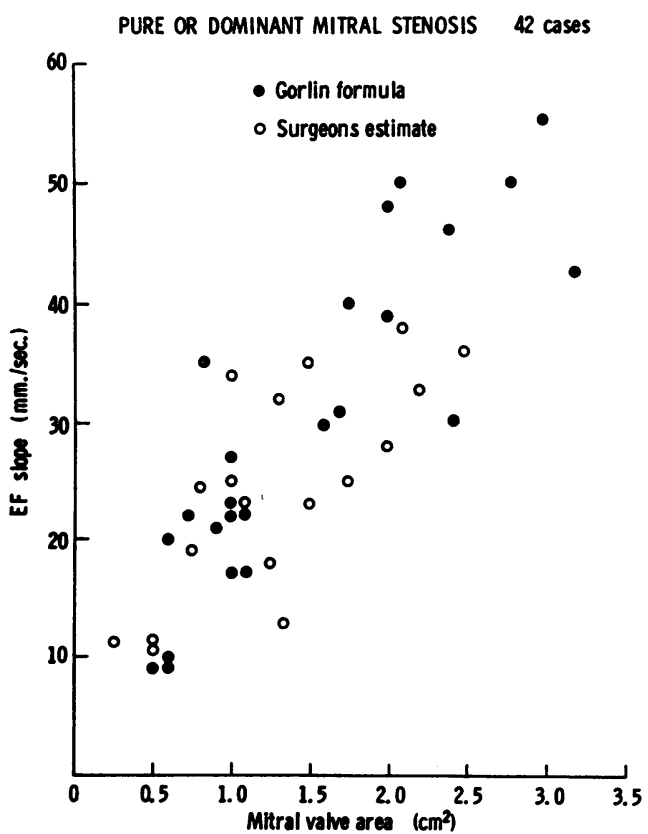




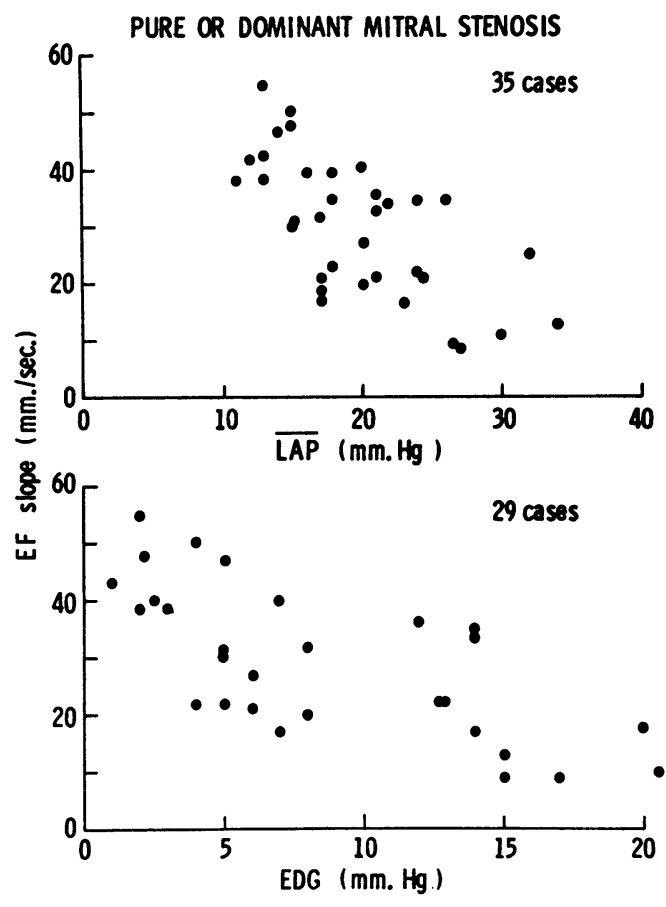

FIG. 7 EF slope plotted against mean left atrial pressure (LAP) and end-diastolic gradient (EDG) in patients with mitral stenosis.

with the findings of other workers (Gustafson, 1966; Winters et al., 1967b; Gustafson, 1967; Winters, Gimenez, and Soloff, 1967a). Pre-operatively, provided there is an amplitude of movement of over $10 \mathrm{~mm}$., the decrease of the EF slope correlates with the degree of mitral stenosis. In patients in whom the amplitude is below ro mm., though the EF slope usually gives no direct indication of the degree of stenosis, the mitral valve is rigid and very distorted and requires replacement (Edler, 1966).

The authors wish to express their thanks to Dr. D. C. Deuchar and the late Dr. G. C. Baker for their support and encouragement, to the members of the Cardiac Department at Guy's Hospital for their collaboration, and to Smith Kline Instruments Ltd. for their help and loan of the apparatus.

\section{References}

Edler, I. (196I). Atrioventricular valve motility in the living human heart recorded by ultrasound. Acta Medica Scandinavica, Suppl. 370, 83.

- (1966). Mitral valve function studied by the ultrasound echo method. In Diagnostic Ultrasound: Proceedings of the First International Conference, University of Pittsburg, 1965, p. 198. Plenum Press, New York.

- Gustafson, A., Karlefors, T., and Christensson, B. (I96I). Mitral and aortic valve movements recorded by an ultrasonic echo method. An experimental study. Acta Medica Scandinavica, Suppl. 370,67 .

$\longrightarrow$, and Hertz, C. H. (1954). The use of ultrasonic reflectoscope for the continuous recording of the movement of heart walls. Kungliga Fysiografiska Sällskapets $i$ Lund Förhandlingar, 24, 5.

Effert, S. (1967). Pre- and post-operative evaluation of mitral stenosis by ultrasound. American fournal of Cardiology, 19, 59.

Gustafson, A. (1966). Ultrasoundcardiography in mitral stenosis. Acta Medica Scandinavica, Suppl. $46 \mathrm{I}$.

- (1967). Correlation between ultrasoundcardiography, hemodynamics and surgical findings in mitral stenosis. American fournal of Cardiology, I9, 32.

Kingsley, B., Flint, G. B., Jr., Raber, G. T., and Segal, B. L. (1967). Another look at echocardiography. Concepts in biomedical engineering. American fournal of Cardiology, 19, 108.

Segal, B. L., Likoff, W., and Kingsley, B. (1967a). Echocardiography: clinical application in mitral regurgitation. American fournal of Cardiology, 19, 50.

- , and - (1967b). Echocardiography: clinical application in combined mitral stenosis and mitral regurgitation. American fournal of Cardiology, 19, 42.

Wharton, C. F. P. (1968). Ultrasonic patterns in mitral valve disease. In Proceedings of The British Cardiac Society. British Heart fournal, 30, $42 \mathrm{I}$.

- (1969). Reflected ultrasound patterns in mitral valve disease. Guy's Hospital Reports, 118, 187.

Winters, W. L., Jr., Gimenez, J., and Soloff, L. A. (1967a). Clinical application of ultrasound in the analysis of prosthetic ball valve function. American fournal of Cardiology, 19, 97.

-, Riccetto, A., Gimenez, J., McDonough, M., and Soulen, R. (1967b). Reflected ultrasound as a diagnostic instrument in study of mitral valve disease. British Heart fournal, 29, 788.

Yoshida, T., Mori, M., Nimura, Y., Hikita, G., Takagishi, S., Nakanishi, K., and Satomura, S. (I96I). Analysis of heart motion with ultrasonic Doppler method and its clinical application. American Heart fournal, 61, 61. 